\title{
La interpretación heideggeriana de Platón como génesis de la pregunta por el arte
}

\section{Heidegger's Interpretation of Plato as the Genesis of the Question of Art}

\section{Ignacio Soneira}

Facultad de Filosofía y Letras, Univ. de Buenos Aires. Buenos Aires, Argentina. ignaciosoneira@filo.uba.ar

\section{Resumen}

El presente artículo analiza las diferentes posibilidades interpretativas de la conferencia de Heidegger Der Ursprung des Kunstwerkes, con la finalidad de esclarecer las causas y el sentido del abordaje heideggeriano de fenómeno artístico en la década del treinta. En ese camino, el trabajo expone una vía analítica centrada en la relectura de Platón que lleva adelante el autor en 1931, intentado establecer una correspondencia entre arte, política y filosofía. Para llevar a cabo los objetivos propuestos, resulta nodal el desmontar y cotejar las diferentes redacciones de la conferencia, así como sus agregados y epílogos.

Palabras clave: Heidegger, Platón, arte, política.

\section{Abstract}

The present article analyzes the different interpretive possibilities of Heidegger's Der Ursprung des Kunstwerkes conference, with the purpose of clarifying the reasons and the sense of the heideggerian's boarding of artistic phenomenon in the decade of thirty. In this way, the work exposes an analytical route centred on Plato's rereading that the author takes forward in 1931, trying to establish a correspondence between art, politics and philosophy. To take to end the proposed aims, they turn out to be nodose to dismount and to arrange the different drafts of the conference, as well as his attachés and epilogues.

Keywords: Heidegger, Plato, Art, Politics. 


\section{Introducción}

El origen de la obra de arte (Der Ursprung des Kunstwerkes) de Martin Heidegger es considerado uno de los escritos clave de la discusión estética del siglo XX. De ello nos dejan constancia los manuales de texto específicos, las actas de congresos especializados y la producción contemporánea en este campo disciplinar en autores como Danto, Schaffer o Badiou, por poner algunos ejemplos. Asimismo, toda una tradición interpretativa advierte la marcada relevancia que tiene este ensayo en el conjunto del corpus heideggeriano, tanto al momento de indagar el derrotero conceptual que habita su profusa obra, como a los fines de explorar las relaciones entre su desarrollo especulativo y los contextos históricos en los cuales llevó a cabo su elaboración. En esa clave, Der Ursprung des Kunstwerkes ha sido, junto con el famoso "Discurso del rectorado" (Die Selbstbehauptung der deutschen Universität), uno de los focos de atención abordados para analizar las conexiones de Heidegger con la glosa y el imaginario nacionalista y/o nacionalsocialista. Situación que se desprende de la interpretación de un ensayo que tuvo sensibles e intencionadas modificaciones a lo largo de, al menos, veinticinco años. Es decir, desde el trabajo leído por primera vez en la Sociedad de las ciencias y las Artes el 13 de noviembre de 1935 hasta la versión publicada finalmente en Holzwege, encontramos distancias estructurales. Ellas se hubieran agrandado con el último apartado que Heidegger quería agregar orientado al tratamiento del arte moderno (Petzet 190-3). El cual, de concretarse, se hubiese sumado a los de 1956 y 1960. En rigor, disponemos al momento de la primera redacción del trabajo que data de 1931-1932 ${ }^{1}$, de la versión que Heidegger leyera en 1936, sin aparentes modificaciones de la de 1935, llamada Vom Ursprung des Kunstwerks, y de aquella finalmente publicada en Holzwege en $1949^{2}$. Las distancias en los textos, como mencionamos, son significativas y los apéndices efectivamente resitúan la comprensión en otras latitudes, por lo general cercanas a las preocupaciones tardías de Heidegger. Ellas atraviesan medularmente los intereses cambiantes del autor y, en algunos puntos, reducen el tenor político de las versiones preliminares.

La repentina cercanía al arte por parte de Heidegger promediando la década del treinta, ha disparado un variopinto panorama de hipótesis que, en rigor, intentan demostrar la compatibilidad del tratamiento del arte con la premisas de Sein und Zeit (SuZ) o, por el contrario, el necesario cambio de rumbo que sufre su pensamiento en esos años. Pero ¿cómo y a causa de qué Heidegger llega a la pregunta esencial por el arte? En este trabajo nos proponemos reponer algunas de las principales vías que se

1 En una carta a Elisabeth Blochman del 20 de diciembre de 1935 Heidegger afirma que finalmente había terminado la primera redacción del trabajo sobre la obra de arte comenzado en 1931 (Espinet y Keiling 16). Con esa fecha dató Hermann Heidegger el manuscrito encontrado y publicado en Heidegger Studies (5-22).

2 Sobrevilla sostiene que aún existen manuscritos inéditos en el Nachlass heideggeriano y que entre ellos estaría el original de 1935. 
han presentado en los últimos años para, finalmente, esbozar un camino aún magramente transitado y que se vincula con los cursos sobre Platón que Heidegger dictara en 1931(Vom Wesen der Wahrheit). En rigor, la reflexión heideggeriana sobre el arte regularmente asociada a su acercamiento a Nietzsche y a Hölderlin, encubre una particular recepción de Platón y su discusión en torno al valor de la poesía en el marco de la fundación de un Estado. En esa clave, es menester analizar las caracterizaciones de Arte, Verdad y Educación en clave política, presentes en el curso mencionado, a los fines de vincularlo con la primera redacción de la conferencia dedicada al arte -Vom Ursprung des Kunstwerks- que data del mismo año. Para llevar adelante nuestros objetivos nos apoyaremos en la interpretación que Gadamer efectuara en Marburgo en 1934 bajo el formato de una conferencia, Plato und die Dichter. No resulta azaroso que ambos autores recuperen el desarrollo que Platón hiciera en La República, en un contexto en el cual la redefinición del arte, la educación y la política se presentaban como emergentes.

\section{Antecedentes}

Las conferencias de Heidegger destinadas al arte, ubicadas promediando la década del treinta, se han utilizado, como mencionamos, para establecer continuidades o necesarias rupturas con el Proyecto SuZ. No podemos desconocer en ese sentido, que las referencias al arte previas a aquellos años son marginales. Apenas comentarios a propósito del lenguaje poético en el marco de la descripción del habla (Rede) en su tratado fundamental o en cursos preparatorios, aclaraciones en torno a la imagen en trabajos como Logic. Die Frage nach der Wahrheit y menciones aisladas a la música. Ahora bien, antes que hacer la pregunta acerca de si la manera en que Heidegger piensa el arte se enmarca en el aparato conceptual de $S u Z$ o da lugar a otro, vale la pena indagar cuál es la relación efectiva de Heidegger con el arte. Ya que, en efecto ¿éste quiere analizar el arte o quiere complejizar el concepto estético incorporando al arte como instrumental teórico a su especulación filosófica?

La influencia que tiene el arte en la vida y en la obra de Heidegger no puede reducirse a una tradición, un conjunto de artistas o categorías estancas. Desde sus tempranas lecturas de Stefan George pasando por sus encuentros con Chillida, hasta los proyectos truncos de escribir sobre Cézanne o Klee, nos topamos con una repetida preocupación por un fenómeno que se encontraba en creciente efervescencia pasadas las primeras décadas del siglo XX. Vale destacar que su ensayo dedicado al origen de la obra arte aparece en un clima en el que convivían la Bauhaus, la música dodecafónica de Schönberg y Webern, la pintura de Kandinsky y en el que las vanguardias multiplicaban y radicalizaban sus propuestas. Asimismo, la dominante utilización del arte en sus condiciones de reproductibilidad con fines comunicativos y, básicamente, políticos -como nos va demostrar Walter Benjamin por esos mismos años-, da lugar 
a un escenario en el cual ruptura de la tradición, exploración formal y sentido político convivían en tensión. En esa clave, las discusiones relativas a la oposición realismoformalismo, transitaban el inevitable ingreso del arte en la publicidad, el diseño y el mercado. En el corazón de esos enfrentamientos, todo el arco político desplegado entre la restauración conservadora y el comunismo.

Es complejo precisar el real conocimiento de Heidegger de lo que estaba ocurriendo en "el mundo de la producción artística", sus debates internos y posiciones. Tan complejo como advertir en qué medida su ensayo está ofreciendo una perspectiva más en ese remanido entramado. Heidegger posiblemente tenía un conocimiento superficial de la Bauhaus para la década del treinta ${ }^{3}$, también de la pintura abstracta, aunque guardaba en general una valoración negativa hasta su encuentro tardío con la obra de Klee (cfr. Petzet 179). Incluso pueden entenderse sus constantes alusiones a la "explotación organizada del arte" (Kunstbetrieb) como un rechazo a la industria artístico-cultural, que se irá aclarando y complejizando con el correr de las décadas. Menos referencias aún encontramos de su conocimiento del Dadaísmo, el Constructivismo o el Suprematismo. De todos modos, recorriendo sus cursos y trabajos de comienzos de 1930, es evidente que el fenómeno artístico contemporáneo no le resultaba mayormente significativo. En ese sentido, su atención estaba puesta en los clásicos, fundamentalmente los griegos. Su cercanía a Hölderlin, manifiesta en sus cursos sobre Germania y el Rhin, y su temprana participación en los círculos de lectura de la obra de George, exponen el recorrido circundante del profesor de Friburgo.

No obstante, este "espíritu clásico" se irá ampliando con el correr; de los años hasta desembarcar en el repetido deseo de Heidegger de aumentar la conferencia de 1935 con un pendent sobre arte moderno, en el que intentaría dejar en evidencia su cercanía a la esencia de la técnica y su definitiva distancia del arte de la antigüedad ${ }^{4}$. En esa línea, se entiende la tardía incursión del ejemplo de Van Gogh en la conferencia sobre arte, que ha signado la interpretación del trabajo en los últimos años (cfr. Soneira). En rigor, las redacciones preliminares de la conferencia de Heidegger se encuentran situadas básicamente en el arte clásico. Recién en la revisión tardía que publicara finalmente en 1949, va a incorporar elementos y referencias del campo artístico moderno y una alusión a la discusión estética, en el cual se posiciona a partir de un llamamiento a la filosofía del arte (Sobrevilla, "El origen de la obra de arte según Heidegger" 364). No es casual en ese sentido, que omita una discusión con el modelo canónico Baumgarten-Kant en el desarrollo del ensayo pero que, a la vez, resitúe su interpretación en dicho ámbito con el epílogo de 1957. Sin ir más lejos, allí el autor de la conferencia apelando a la sentencia de Hegel sobre el carácter pasado del arte,

3 Tendríamos que asumir ello dado que tenía contacto en la década del treinta con Moholy-Nagy, el maestro de Bauhaus (Cfr. Petzet 24).

4 En relación al pendent sobre arte Moderno, posiblemente el único indicio de la dirección que tomaría este trabajo la tenemos en el breve ensayo de 1969 Die Kunst und der Raum. Para este tema cfr. Hildebrandt T. "Bildnerisches Denken. Matin Heidegger und die bildene Kunst" (Espinet 210-225). 
reinserta la reflexión en el territorio delimitado por la teoría del arte y la estética. La referencia a Hegel resulta conveniente por el hecho de que éste también era adverso a la estética y en consecuencia proponía una filosofía del arte que no reduzca el fenómeno artístico al juicio estético (cfr. Hegel, Lecciones sobre la estética 56). A la vez, la alusión a Hegel reincorpora una dimensión romántica, efectivamente vigente en Heidegger hasta la década del setenta ${ }^{5}$.

\section{Discusión de resultados}

\section{Arte: ¿Giro o continuidad con SuZ?}

En el Zäringen Seminar de 1975 Heidegger asegura que la meditación sobre el origen de la obra de arte había jugado un rol decisivo en la Kehre (Taminiaux, "The Origin” 392). En esa línea, no son pocos los autores que entienden que dicho trabajo constituye un punto de inflexión para sostener la posibilidad de un cambio de coordenadas en su pensar. En rigor, allí no sólo se establecería un giro desde el existente humano hacia la comunidad ${ }^{6}$, sino también en la consideración sobre la historia, en el paso de una historicidad del Dasein a la historia del ser entendida como Ereignis (Vattimo, Introducción a Heidegger 178) y en el método para la filosofía (Volpi, "La Question du Logos"). En ese sentido, vale la pena atender a la etiología de la pregunta por el arte en el contexto del desarrollo interno de la ontología heideggeriana a los fines de sostener o negar una genuina ruptura con las premisas del proyecto Ser y tiempo.

Una de las primeras claves para pensar la premisa de una continuidad o una ruptura con $S u Z$ reside en la reinterpretación para la década del treinta de los conceptos aristotélicos Frónesis, techné y teoría. Los múltiples cursos sobre el Estagirita que Heidegger dicta desde su juventud lo conducen a una "apropiación ontológica de sus principales conceptos" (Volpi, "La Question du Logos" 34). Dicho proceso se proyecta en la compleja economía de SuZ. Autores como Jacques Taminiaux sostienen que la problemática del arte se debe a una reconsideración del concepto de techné en la Ética nicomaquea pero que de ningún modo la primera o la segunda redacción ofrecen indicios para pensar un giro en relación a la ontología fundamental de SuZ. En efecto, el desarrollo en torno una "concepción menor de la techné" y una "techné mayor", tal y como es presentada en la versión preliminar a la conferencia, no se aleja considerablemente de lo auténtico-inauténtico o de una temporalidad vulgar frente a una originaria. Para Taminiaux, el hecho de que no se hable de Dasein sino de pueblo

5 Para este tema cfr. el trabajo de Sebastian Schwenzfeuer "Vom Ende der Kunst. Eine Kurz Betrachtung zu Heideggers Kunstwerkaufsatz vor dem Hintergrund des Deutchen Idealismus" (Espinet y Keiling 139-160).

6 También presente en otras textos de época como Logik als die Frage nach dem Wesem der Sprache (1934) o los cursos Hölderlins Hymnen "Germanine" und "Der Rhein" (1934-35). 
tampoco introduce una novedad significativa dado que lo fundamental sigue siendo la decisión (399). En definitiva, sólo los múltiples agregados y las ulteriores modificaciones reinsertarían a la conferencia en otras coordenadas, ahora sí lejanas de SuZ. En esa perspectiva, el Addendum de 1960 resulta vital para esta interpretación, ya que resitúa al ensayo en el marco de la pregunta por el acontecimiento (Ereignis). Es decir, donde opera un verdadero descentramiento del existente humano, la historia no es unilateralmente la del Dasein y no hay casi lugar para la decisión.

Otra de las claves para pensar en una continuidad con $S u Z$, reside en el análisis del concepto de imagen (Bild) en el marco de las repetidas lecturas por parte de Heidegger de la obra de Kant. En esta perspectiva de indagación, Roberto Rubio en "Heideggers Orientierung auf die Dichtung in der Übergangsphase nach Sein und Zeit“, ofrece evidencia de que la aproximación al arte por parte de Heidegger "resulta de la crisis y transformación de su recepción del esquematismo kantiano" (79). Heidegger al desarrollar su versión del esquematismo kantiano retoma de La Antropología en sentido pragmático, la caracterización de la imaginación productiva como poética (dichtend). Ahora bien, la cuestión del arte para este autor se inscribe en la formulación de un "esquematismo heideggerino" enfocado hacia la producción de imágenes o figuras como ehhibitio originaria. En ese sentido, la poesía como Dichtung tendría que ser pensada como "producción" en el sentido específico de la formación de imágenes no reproductivas. Vale atender por ello a los ejemplos utilizados en la primera redacción de "El origen de la obra de arte". Allí Heidegger menciona la estatua de Apolo, el templo de Zeus, la tragedia Griega y la poesía de Hölderlin. Es decir, se concentra en el ámbito de la escultura, la poesía y la construcción. Así "la imagen o figura (Bild) es entendida en el sentido eminente de "estatua" o "figura estante" (Standbild) [...] lo relevante no es si la estatua "representa" tal o cual cosa sino que ella remite al suelo a donde se asienta y a lo alto, hacia donde se yergue, y a la vez hace patente su irrupción en el espacio" (Rubio 7). Bajo esa función, el "poner en obra" debe ser entendido como el "parar" (zum Stehen bringen) de la verdad en la obra. Como afirmamos, esta formulación se desprendería directamente de la lectura y apropiación kantiana del concepto de Bild ${ }^{7}$. Sólo a partir de los cambios en el texto realizados en los años posteriores a la primera redacción se lograría entonces borrar la traza de estos desarrollos que vinculan indefectiblemente al "primer Heidegger" con el ensayo sobre arte.

Por último, otra de las claves que hemos explorado en otros trabajos (Cfr. Soneira) nos posiciona frente a la necesidad de Heidegger de apelar al arte -en particular la poesía- para solventar las deficiencias del lenguaje de la descripción fenomenológica en la analítica existenciaria. Dado que el desarrollo de este tópico nos insumiría una

7 Este tema, no obstante, ya había sido tratado por Heidegger varios años antes en Logik. Die Frage nach der Wahrheit. En ese curso de 1925 Heidegger habla de la "representación figurativa en el arte y sus medios para constituir sentido" (Heidegger 286-7). 
extensión desproporcionada con el presente artículo, nos limitaremos a mencionar algunos caminos a través de los cuales se puede encontrar una correspondencia entre la apelación al arte en la década del treinta y el proyecto Suz:

Si tomamos, la "función presentativa" o "delótica" del lenguaje en $\operatorname{Suz}(\$ 7$ y $\$ 14)$ y las referencias al arte como un "nombrar fundador" en El origen de la obra de arte e Introducción a la Metafísica; nos encontramos con un paralelo estructural entre la función descriptiva dentro del método hermenéutico y el arte a partir de los '30. La correspondencia es clara: el "nombrar" o "decir proyectante" que compone el arte tiene un tratamiento idéntico y cumple la misma función estructural que "la determinación de algo como algo" (ansprechen etwas als etwas) en el proyecto Suz. En ese sentido, las coordenadas bajo las cuales fue explicitado el lenguaje de la descripción fenomenológica como una forma de apertura, aparecen en 1935 en el mismo horizonte en el que es presentado el arte como aquello que da sentido de mundo, sobre todo en la primera redacción de la misma.

Otra indicación, trabajada por varios investigadores en los últimos años, reside en la lectura que se puede establecer a través de la función del silencio (Schweigen) en una y otra etapa. En efecto, el silencio es la modalidad propia del lenguaje en el marco de Ser y tiempo y va a quedar relegado al territorio del arte a partir de los años '30 (cfr. Carrillo Canán, "Poesía e interpretación en Heidegger"). Por último, la función de la Dichtung, como la condición de posibilidad de palabra a partir de los años `30 (especialmente en Logik als die Frage nach dem Wesen der Sprache), recibe una caracterización isomórfica a la que es asignada al Rede (o la relación entre comprender y habla) en Suz u otras formulaciones anteriores (Soneira 72).

El ensayo sobre arte de 1935 en su primera redacción y en los comentarios en torno a su primera lectura son absolutamente coherentes con el desarrollo de la ontología fundamental presentada en Suz. Dicha situación se torna problemática con las modificaciones operadas sobre la primera redacción, el epílogo de 1957 y, fundamentalmente, el Addendum de 1960 en el cual la lectura del arte se encuentra condicionada por su "función fundadora" de sentido histórico (Ereignis).

\section{El sentido político de la obra de arte}

Las lecturas políticas sobre la producción de Heidegger en los años treinta abundan, sobre todo aquellas que ponen el foco en las ideas que se desprenden de un conjunto de cursos y escritos como el discurso del rectorado (1933), Logik als die Frage nach dem Wesem der Sprache (1934), los cursos Hölderlins Hymnen "Germanine" und "Der Rhein” (1934-35), Einführung in die Metaphysik (1935) y claro, Der Ursprung des Kunstwerkes. 
Es Pöggeler quien sostiene en Filosofía y política en Martin Heidegger que el ensayo sobre arte está directamente vinculado a la negativa de Heidegger a dictar un curso sobre el Estado (cfr. 157), cuestión que se conectaría con su alejamiento definitivo del nazismo. A su vez Petzet, asegura que la conferencia no pudo publicarse en ese momento -1935- "porque difería demasiado de la ideología artística oficial, proclamada por Goebbels y Rosenberg como dogma nacionalsocialista” (178). Desde el otro polo, Víctor Farías pretende demostrar que la filosofía de Heidegger en su conjunto es absolutamente compatible con el nazismo a través de un exhaustivo y posicionado análisis (Farías). En el mismo tono, autores como C. Long vinculan a la conferencia dedicada al arte con el "nazismo de Heidegger" apelando al paralelo entre lo clásico y lo germánico presente en el ejemplo del templo griego. Esta afinidad espiritual entre ambos pueblos, rescata Long, se encontraba ya en las páginas de Mein Kampf de Adolf Hitler. Ello sería confirmado por el uso repetido de palabras de clara procedencia y carga simbólica como Erde, Boden, Kampf, Streit y Polemos. Acentuado aún más por la referencialidad entre la obra de arte y "el destino de un pueblo histórico" (Geschick eines geschichtlichen Völkes), el "fundamento patriótico" (heimatliche Grund), el "sacrificio esencial" (wesenliche Opfer) y la "fundación de un estado político" (staatgründende Tat) (Long 104). Para Long: "el arte es el lugar para el rejuvenecimiento del Dasein histórico del pueblo alemán. La relación genuina con el arte no consiste meramente en un ejercicio filosófico de estética, sino concretamente, en un cambio político" (Ibíd.).

Desde una perspectiva similar, Luis Rossi en "La Tierra y las imágenes de la comunidad ideal en El Origen de la obra de arte, de Martin Heidegger" formula una correspondencia entre los ejemplos de obras de arte que presenta Heidegger a lo largo de su conferencia y la estética oficial del nacionalsocialismo. Por un lado, el canon clásico, estrechamente emparentado a Olimpia de Leni Riefenstahl o a las producciones del escultor Arno Breker y el arquitecto Albert Speer, "quienes junto con Riefenstahl tuvieron una participación fundamental con la estetización de la política en el nazismo" (Rossi 161). Incluso en la utilización de ejemplos como el del cuadro de los zapatos de Van Gogh (Les Souliers) se encontrarían elementos de la "estética oficial", manifiestos en "la representación sentimental de la vida rural, propia de la ideología völkisch de la <tierra> y la <sangre> ", que se desprenderían de la descripción de unos zapatos de campesina.

Para un análisis acertado de esta problemática resulta conveniente poner el foco en las diferentes redacciones realizadas por Heidegger entre 1931 y 1952, en el valor hermenéutico que tienen los agregados y, en este caso, los recortes o modificaciones

8 Si bien la exaltación de la vida campesina fue propia del ideario nacionalsocialista, no podemos asegurar que ese sea el origen del ejemplo de Heidegger. De hecho, su rechazo a la técnica y a la valoración de "lo cercano al terruño" datan de las épocas de estudiante de Heidegger y se vinculan mucho más a su temprana formación en torno al integrismo católico que a la estética oficial nacionalsocialista. De esa época se registran algunos artículos suyos en el diario católico Heuberger Volksblatt. 
posteriores a 1935. En rigor de verdad, si atendemos a la primera redacción, la remisión a las grandes decisiones del pueblo alemán', la empatía con el pueblo griego y su vinculación a la inminente llegada del destino histórico; es expresa. Todas estas alusiones bajan su tono notablemente en la versión finalmente publicada en Holzwege. Allí las referencias a lo político son veladas y marginales. Si bien es cierto que se mantienen "las fuerzas creadoras del Dasein histórico" entendidas como: el cuestionar del pensador, el sacrificio esencial, las potencias de arte y la fundación de un estado; las menciones resultan casi inentendibles en el marco que propone la publicación a partir de 1949. Heidegger con las modificaciones y los epílogos pretende redireccionar la interpretación política que podría desprenderse de su ensayo, primero al ámbito de la reflexión pura sobre el arte (filosofía del arte) y luego a la problemática del Ereignis; preocupaciones sensiblemente posteriores a las que abordara originalmente el ensayo. La cercanía entre el arte y la política va a resultar diáfana una vez esclarecido el lugar de Platón y su expulsión de los poetas en esta trama.

\section{Política, Arte y Educación del pueblo en la República de Platón}

En el semestre de invierno de 1931/32 Heidegger ofrece unas lecciones en la Universidad de Friburgo destinadas a la interpretación del pensamiento de Platón a partir de un comentario minucioso del Teeteto y de la conocida "Alegoría de la Caverna", desarrollada en República libro X. El curso, titulado Vom Wesen del Wahrheit, va a ser repetido con ligeras -aunque no desestimables- modificaciones en el semestre de 1933/1934 y publicado por Heidegger en una versión abreviada en 1942 en Geistige Überlieferung. En cada uno de esos momentos, revisar las tesis de Platón sobre la Polis, más allá de la recurrente intención de Heidegger por desviar el análisis hacia cuestiones ontológicas, gnoseológicas y hasta filológicas, reviste un evidente sentido político vinculado a las circunstancias contextuales, aunque éstas sean distintas en cada caso. El sendero de indagación de la Polis griega cobrará densidad en trabajos ulteriores como su curso dedicado al pensamiento de Parménides de 1942 y se inscribe en una reflexión general en torno al concepto de Estado que desarrollará en diferentes escritos y cursos entre 1930 y 1943 . No obstante, la reinterpretación de la República platónica no pudo haber sido una novedad en los convulsionados albores de la década del treinta en Alemania, sobre todo si tenemos en cuenta la antigua intención por parte del romanticismo alemán y del posterior nacionalismo de encontrar una afinidad esencial con el espíritu de los griegos, que tomará un sentido programático con la configuración del ideario nacionalsocialista.

Sin ir más lejos, Heidegger mismo abona esa vía con sus palabras inaugurales del curso de 1933 La pregunta fundamental de la filosofía, cuando, a propósito del

9 "Wirklicher denn all dieses ist die Dichtung, weil in ihr den Deutschen die noch unbetretene Mitte ihrer Welt und ihrer Erde bereitet ist und groBe Entscheidungen aufgespart" (Heidegger 37). 
momento en el que cobra relevancia la indagación que da nombre al curso, sostiene: "en el punto en el cual el pueblo griego, cuya etnicidad y lenguaje tiene la misma proveniencia que la nuestra, puso a crear a sus grandes poetas y pensadores un único modo de existir (Dasein) de los hombres" (Heidegger 5).

En esa clave, resulta esperable que interrogue retóricamente a sus estudiantes sobre la importancia de volver al viejo texto de Platón en aquél primer curso de 1931: "estos paseos inofensivos por los viejos jardines de visiones del mundo y doctrinas antiguas ¿no es un cómodo eludir la responsabilidad frente a las exigencias del día, un lujo espiritual extravagante que ya no legitima ningún derecho (y hoy menos que nunca)?” (19). Ineluctablemente, contestará: “el auténtico regreso a la historia [...] es el impulso necesario para saltar más allá de nuestro propio presente" (21). En rigor, "el regreso a la historia nos lleva por primera vez a lo que hoy sucede realmente", resultando "el comienzo decisivo de la auténtica futuridad" (Ibíd.).

El "nuevo inicio", augurado con posterioridad a la crisis de 1929, encontrará su carnadura en un "paso atrás" y, particularmente, con la metáfora de un esclavo que luego de tener acceso a la verdad, volverá al mundo de las apariencias a comunicarla, aún bajo el peligro inminente de ser asesinado por sus pares. El sentido de hacer filosofía en un contexto de crisis no podrá ser más explícito en el desarrollo del curso.

El camino indicado para seguir la lectura del relato alegórico de la obra fundamental de Platón, se estructura, decíamos, en un comentario de la fuente griega a partir de cuatro estadios (la situación del hombre en la caverna subterránea, la liberación del hombre dentro de la caverna, la auténtica liberación del hombre para la luz original y el descenso de regreso del libre a la caverna). Aunque el itinerario del curso anuncia desde sus primeras líneas una "libre" interpretación por parte de Heidegger, práctica común si advertimos la enorme revisión de la historia de la filosofía desde una perspectiva absolutamente funcional a los esquemas especulativos de su propio desarrollo teórico, éste insiste en seguir el texto griego de forma analítica. Es así como exalta la imposibilidad de traducir y aplicar caracterizaciones de "término medio" en el aparato conceptual presentado por Platón, algo que había ya llevado adelante, como mencionamos, con sus repetidas relecturas de la obra de Aristóteles en años precedentes tanto en Marburgo como en Friburgo. Uno de estos conceptos es el de $\pi \alpha \iota \delta \varepsilon \_$que, si bien comúnmente es traducido por educación, remitiría a un "cambio de dirección de todo hombre en su esencia” (Heidegger 182). Por tanto, la palabra del alemán que mejor respondería, según Heidegger, a una malograda traducción sería Bildung, la cual requiere no obstante una restitución de su "fuerza significativa originaria” (Ibíd.). En efecto, la palabra Bildung mantiene la raíz de Bild, imagen. Por ello, dicha restitución para Heidegger implica definir Bildung como "imprimir carácter y dejarse guiar por una imagen” (Ibíd.) ¿Qué sentido propone esto en el contexto argumentativo que venimos proponiendo? La respuesta nos remite denodadamente al uso filosófico de la imagen y por qué no, al del arte. Pero ¿"arte” para hablar de Educación? ¿Arte para explicar la alegoría de la caverna? Veamos. 
Desde el comienzo del curso Heidegger habla de la necesidad de guiarse por una "imagen simbólica", un indicador para guiar a la indagación filosófica. De hecho, sostiene que Platón para exponer su consideración de la verdad $(\alpha \lambda \eta \theta \varepsilon\llcorner\alpha)$ no suele apelar a una definición ni a un desmembramiento conceptual, sino a una parábola (Heidegger 28). En rigor, "obedece a una necesidad interna que, siempre que Platón quiere decir en filosofía algo último y esencial, hable en parábolas y nos ponga ante una imagen simbólica” (29). Empero ¿cómo debemos entender el uso de la parábola para el fin de la exposición del concepto?

Hablamos de una 'parábola'. Decimos también: Sinn-Bild, 'imagen simbólica', 'imagen con sentido'. Eso significa: una imagen visible, de modo que lo contemplado hace de inmediato una seña. La imagen no quiere ser considerada por sí misma: hace una seña, una seña hacia el hecho de que hay algo que entender en esta imagen y mediante esta imagen, y hacia qué sea eso. La imagen hace una seña [...] hacia un sentido, Sinn (de ahí: Sinn-Bild) (28).

La imagen opera entonces como un indicador de la comprensión, una guía hacia el concepto filosófico. El recurso no parece alejarse de la caracterización de indicación formal (formalanzeige) presentada en el marco del Proyecto Sein und Zeit y abandonada paulatinamente en años posteriores a su publicación. La sensible diferencia radica en el hecho de que ahora aquello que indica la comprensión, lo que hace una seña hacia un ámbito de inteligibilidad no determinado materialmente, no es un concepto cuya referencia se encuentra abierta, sino que es, efectivamente una imagen, una metáfora. Por ello dice: "el hacer señas que nos da visiblemente una imagen, nos conduce: hacia aquellos que ni el mero describir, por muy fiel que sea, ni tampoco el demostrar prosaico, por muy estricto que sea, jamás llegará a aprender" (29). Porque estos asuntos no pueden, según la palabra de Heidegger, ni describirse ni demostrarse. El sendero de la reflexión filosófica hacia las condiciones de posibilidad de lo dado se transita, como describiera en gran parte de su filosofía temprana, en una vivencia no objetivable, lejana a la forma de acceso al fenómeno que propone la ciencia.

Pero Heidegger vuelve en el mismo curso a utilizar la palabra Bild para definir a la idea platónica. En vías de caracterizar al filósofo como aquel hombre que tiene el deseo de saber, afirma:

El verdaderamente ávido de aprender (quien verdaderamente quiere saber) se dirige a lo ente y no atribuye valor a lo que sólo se considera como tal. No se

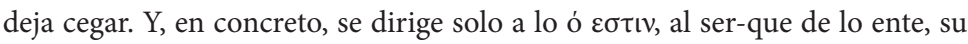
esencia, las "ideas", lo onticamente ente. Las ideas son, por tanto, lo ente más ente: imagen (Bild), visión, $\varepsilon 1 \delta \circ \varsigma$ (74).

Una imagen (Bild) es, efectivamente, aquello que se adecúa con lo propiamente no-oculto, un espacio de iluminación en el que se hace visible lo existente. Lo cual hace posible caracterizar, siguiendo el esquema platónico, a la $\alpha \lambda \eta \theta \varepsilon ı$ en términos de Lichtung. 
Hasta aquí encontramos una sintonía a partir del uso de la palabra Bild entre $\pi \alpha \iota \delta \varepsilon \_$, definida como un cambio de dirección en el dejarse guiar por una imagen; Idea, como aquello que se presenta como lo no-oculto o lo desocultado y alegoría (o indicador formal), en tanto imagen simbólica que constituye el camino filosófico hacia la verdad de la idea, la claridad entendida como $\alpha \lambda \eta \theta \varepsilon \iota \alpha$. De todos modos, no hemos vinculado aún nuestra presentación con el arte. Para ello deberíamos en primer lugar seguir la recomendación que Heidegger mismo le hace a sus estudiantes en el curso: para entender qué es la obra de arte y el arte poético, "la filosofía tiene que primero desacostumbrarse de concebir el problema del arte como un problema de estética" (70). Ello nos conduciría a pensar al arte en su esencia, con anterioridad a la concepción estética instalada a partir de la Modernidad.

Como anunciamos, del mismo año que este curso data la primera redacción de $E l$ Origen de la obra de arte (1931). La lectura de Platón sobrevuela todo el ensayo, aunque su impronta irá desapareciendo en las versiones posteriores. Esta presencia no es solo cronológica, el filósofo griego había advertido en su tratado la singular correlación entre Arte, Política, Educación y Verdad. La inspiración resulta entonces evidente: Heidegger inaugura su reflexión sobre el arte en el territorio delimitado por Platón en su República. La evidencia de dicha afirmación se desprende de la lectura conjunta de ambos trabajos.

En Vom Ursprung des Kunstwerkes, Heidegger sostiene que la interpretación de la obra de arte como alegoría y símbolo, tiene sus orígenes en el modelo ontológico platónico en el cual se propone un distinción entre lo sensible y lo suprasensible; destacando el hecho de que la mentada postulación, bajo el dominio del pensamiento cristiano, dio lugar a la caracterización del arte entendido como representación (Darstellung). Es menester destacar que la apelación a Platón que hace Heidegger, viene a cuento de demostrar el carácter falente de la concepción representacionista de arte. En efecto, Platón en República VII expone una crítica al arte, dando cuenta de su forma ontológica degradada. El ejemplo utilizado por el filósofo griego para graficarlo es el de las artes visuales. En él retoma el caso de una pintura que imita a una cama, que a la vez es copia de una idea de cama. Heidegger se hace eco de esta crítica para dejar en evidencia que la obra pensada como mímesis o representación, resulta insuficiente para dar cuenta del sentido ontológico del arte, condenándola, en definitiva, al ámbito de la irrealidad.

Para Heidegger la obra de arte no representa sino que, en la disputa entre Mundo y Tierra, hace posible la apertura: la claridad (Lichtung) ${ }^{10}$. Es decir, instala una realidad en tanto tal y por tal motivo en la esencia del arte opera una inversión del planteo platónico: el arte se encuentra, desde ese esquema ontológico, mucho más cercano a la idea (Bild) que a la apariencia o la representación degradada. Heidegger

10 "Aber das Kunstwerk stellt nichts dar; und diez aus dem einzigen und einfachen Grunde, weil es nichts hat, was es darstellen soll. Denn indem das Werk in der Berstreiten des Streites von Welt und Erde diese je in ihrer Weise eröffnet, erstreitet das Werk allerest das Offene, die Lichtung, in deren Licht das Seiende als solches uns wie am ersten Tag oder -wenn alltäglich geworden- verwandelt begegnet" (Heidegger 34). 
erradica la concepción del arte entendido e términos de apariencia, así como Platón, con un gesto aún más radical, expulsa a los poetas de la Polis.

En ese sentido es que debe ser comprendida la instalación (Aufstellung) del templo griego, la catedral de Naumburger o la poesía de Hölderlin. Ésta última "es lo más real, porque en ella les está preparado a los alemanes el medio inexplorado de su mundo y su tierra, y quedan pendientes las grandes decisiones" (Heidegger 36).

En rigor, el arte concebido como institución y fundación, mantiene el estrecho sentido de la palabra $\alpha \lambda \eta \theta \varepsilon ı$. Ahora bien, éste no es ni el de un individuo ni el de una sociedad "sino el de la historia bajo la forma de un pueblo" (48) que debe asumir su destino esencial.

Si bien la concepción de historia vigente es claramente la de $S u Z$ y no aún la del Ereignis, Heidegger anuncia un vinculación entre la fundación de un mundo con las épocas históricas, asumiendo una correlación entre la filosofía y el decir proyectante de la poesía. En dicha clave son comprensibles las palabras del curso sobre Platón:

La esencia el arte no es ser expresión de una vivencia, no consiste en que el artista exprese en la obra su "vida anímica", para que épocas posteriores, como opina Spengler, tengan que preguntar cómo se manifestaba en el arte el alma cultural de una época. Tampoco en que el artista reproduzca la realidad más precisa y nítidamente que otros, o que produzca (exponga) algo en lo que otros tengan un disfrute, un deleite de tipo superior o inferior (Heidegger, $D e$ la esencia de la verdad 70).

Sino que, para Heidegger "lo esencial del descubrimiento de lo real no sucedió ni sucede mediante las ciencias, sino mediante la filosofía original y mediante la gran poesía y sus proyectos (Homero, Dante, Shakespeare, Goethe). La poesía hace a lo ente más ente" (70). El paralelo hasta aquí es evidente: el arte guarda una afinidad esencial con la verdad entendida como alétheia, así como lo era el pensar fundamental de Platón; se encuentra investida con la facultad "lumínica" de revelar e instalar y cumple una función eminentemente política: fundar una nación o pueblo histórico. Proyecto en alguna medida contemplado en los objetivos de República. Sin embargo, hemos destacado la utilización por parte de Heidegger de la crítica platónica al arte pero no hemos aún aclarado como la caracterización positiva de arte que deja entrever Platón en su tratado, se encuentra a la base del planteo heideggeriano. Para ello nos valdremos de un trabajo contemporáneo al de Heidegger de H.G. Gadamer sobre el asunto.

En 1934 y en un clima ya atravesado por la llegada del nacionalsocialismo al poder, H. G. Gadamer presenta un trabajo titulado Plato und die Dichter, en el cual ensaya una interpretación de la argumentación de Platón acerca del arte. Pero ¿qué tiene para decirles a la Alemania del '30 una revisión de la República de Platón?¿De qué manera esta vieja articulación entre Arte, Estado, verdad y Filosofía podría brindar un horizonte para asumir un "destino"? Gadamer, con un espíritu similar al de Heidegger, lo confirma desde las primeras líneas de la conferencia: 
Comprender en su sentido y razón esta crítica platónica a los poetas es acaso la tarea más difícil que sobreviene del modo más duro a la autoconciencia del espíritu alemán, planteándole la discusión con el espíritu de la antigüedad. Pues justo en el arte y en la poesía antigua, el humanismo estético del clasicismo y del romanticismo alemanes reconoció la antigüedad clásica y la reconoció como ideal canónico (Gadamer 87).

El minucioso abordaje de Gadamer, ofrece desde el inicio la posibilidad de pensar el texto de Platón en clave política y, en ese sentido, se muestra dispuesto a discutir con la consideración tradicional que sostiene que el filósofo griego expulsa a los poetas por la incompatibilidad del arte con su planteo ontológico. Por ello dice:

La posición de Platón respecto a los poetas no es una consecuencia de su sistema, que no le permitiese una apreciación más justa de la verdad poética, sino una expresión deliberada de la decisión que ha tomado, impresionado por Sócrates y por la filosofía, contra toda la cultura política y espiritual de su tiempo y su capacidad de salvar al Estado (92).

En dicha clave analítica es que ratifica: "hay que comprender la crítica a los poetas sólo en conexión con esa fundación global del Estado y con motivo del rechazo radical del Estado existente, así como desde su nueva fundación en los términos de la filosofía.” (93). La crítica de Platón al arte y, particularmente, a la poesía, se vincula entrañablemente con el peso que tenía ésta en la $\pi \propto \iota \delta \varepsilon ı$ griega, singularmente en la formación moral de los jóvenes. Es así que advierte que los poetas homéricos tuvieron una influencia destacada en la formación de los jóvenes, fundamentalmente en la conformación de los grandes prototipos de virtud heroica, valor, honor, disposición para la muerte, nobleza, perseverancia, inteligencia entre otros (94). Los valores morales se encuentran a la base de la conformación de un Estado. Por ello resultaría central reconocer los dispositivos a partir de los cuales se trasmiten y consolidan.

Ahora bien, Platón según la lectura de Gadamer depuraría a la República ideal de la actuación de los poetas épicos pero no sin antes instalar la necesidad de una "poesía filosófica", a saber: la poesía dialogal platónica, la que él mismo lleva a cabo. Bajo ese talante afirma:

La poesía platónica dialogal no es ciertamente modelo de aquella poesía que sería permitida en el Estado ideal. Pero es la poesía real que sabe decir la palabra educadora a la vida política real. Y como aquella poesía del Estado ideal se defiende de la comprensión "estética" de su mímesis, también la poesía platónica dialogal tiene que oponerse a una comprensión estética (105).

La presencia de Platón no podría ser más evidente: el filósofo griego expulsa a los poetas de su República ideal, aparentemente por la lejanía de la verdad en la que se encuentran sus relatos, similares a las imágenes de los pintores que imitan una reali- 
dad ya aparente, pero las fundadas razones que justifican tamaño ensañamiento con los poetas, como nos señala Gadamer, obedecen a una convicción eminentemente política. Heidegger, a través de un elegante giro, llega a las mismas conclusiones: advierte el valor formativo del arte $(\pi \alpha \iota \delta \varepsilon\llcorner\alpha)$ en tanto éste implica "un cambio de dirección esencial del hombre”, asume la afinidad estructural entre filosofía y arte y por ello afirma que solo mediante la filosofía y la gran poesía (Dichtung) se lleva a cabo lo esencial del descubrimiento de lo real ${ }^{11}$; y supone el sentido político que reviste la pregunta por la esencia del arte. Solo en esta clave cobrará sentido la famosa afirmación de Heidegger de Der Ursprung des Kunstwerke de que: son los hombres de Estado también capaces de fundar la verdad. Tanto Gadamer como Heidegger citan extensamente en sendos ensayos la carta VII de Platón en la cual éste le relata a un amigo de Sicilia que su escrito sobre el Estado, exige que los filósofos sean los gobernantes, pues únicamente a partir de la filosofía estarían puestos en orden los asuntos estatales. El filósofo implicado en los asuntos políticos, estará entonces a la "escucha del ser", atento a la revelación del mensaje esencial de las grandes obras de arte, en los años posteriores. Pero también fundará sentido con sus propias palabras, guiando al pensamiento hacia los intersticios en donde opera lo no-oculto.

En esa perspectiva, podríamos inscribir un doble uso del arte presente en estos años en la filosofía de Heidegger. Por un lado el arte fundacional, el de los grandes proyectos históricos (el Partenón, La catedral de Bamberg y Hölderlin). Por otro, el recurso artístico como guía para el pensamiento, como Bild-Sinn, como indicador formal. Hilvanando esa trama, podemos retomar el uso de alegorías o imágenes presentado en sus tempranos comentarios a Jaspers. Incluso la apelación a Van Gogh en la última redacción del ensayo sobre arte, como modalidad ejemplar para guiar al pensamiento por medio de aquello que no se podía hacer explícito a través de los conceptos y las concepciones filosóficas de cosa. Heidegger afirma luego de presentar a la obra y lo que ella tiene para decirnos:

Ya hemos dado con el ser-utensilio del utensilio [...] no ha sido a través de la descripción o explicación de un zapato que estuviera verdaderamente presente, tampoco por medio de un informe sobre el proceso de elaboración del calzado [...] Lo hemos logrado única y exclusivamente plantándonos delante de la tela de Van Gogh. Ella es la que ha hablado (Heidegger 25).

Este uso del arte, nuevamente encuentra un paralelo con Platón. Su poesía dialogal como sostenía Gadamer, le permitiría guiarse al hombre por medio de la razón y no a través del dispositivo sensible. Así como la "imagen simbólica” en la alegoría de la caverna, nos haría posible, según Heidegger, guiar la reflexión filosófica sin objetivarla.

11 Asunto que radicalizará en cursos y conferencias posteriores. 


\section{Conclusiones}

A lo largo de este trabajo hemos reconstruido algunos de los posibles abordajes de la conferencia Der Ursprung des Kunstwerkes, dejando en evidencia el carácter problemático de la pregunta inicial por el arte en la filosofía heideggeriana. Ello nos hizo factible advertir que las modificaciones que Heidegger fue realizando a lo largo de los años, no sólo condicionan las interpretaciones y análisis del ensayo, sino que también cristalizan el proceso que el autor hiciera a propósito del arte en diferentes etapas de su vida. La redacción final termina siendo entonces un intrincado entramado que aglutina distintos momentos del pensar heideggeriano, indicando caminos pero dejando huellas de otros que pretendieron ser borrados.

En esa perspectiva, y luego de examinar tanto la compatibilidad del aparato conceptual de SuZ con la conferencia dedicada al arte, como la correspondencia política de ésta con el ideario vigente en la década del treinta en Alemania; iniciamos una exploración circundante a la lectura de Vom Wesen der Wahrheit, curso sobre la alegoría de la caverna de Platón, que aporta una vía aún no transitada para explicar la apelación al arte por parte de Heidegger en aquellos años. Esta perspectiva analítica nos permitió visibilizar un sentido del arte en clave político que no era, como demostramos, absolutamente original en el circuito de ideas en el que Heidegger participaba. La recuperación del ideal griego en la fundación de una nueva república, implicaba la reinterpretación del clásico platónico, con ello una nueva reconsideración del papel del arte en sus dos vertientes: por un lado como un indicador de la comprensión, por otro, como el fundador de un pueblo histórico.

\section{Referencias}

Carrillo Canán, A. J. L. "Poesía e interpretación en Heidegger". La voz del texto. Polisemia e interpretación. Ed. Beuchot, M. México: UNAM, 1998. Medio impreso.

Espinet y Keiling, T. (Hgs) Heideggers Ursprung des Kunstwerkes. Ein kooperativer Kommentar. Frankfurt: Vittorio Klostermann, 2011. Medio impreso.

Farías, Víctor. Heidegger y el nazismo, Barcelona: Muchnik Editores, 1989.

Gadamer, Hans-Georg. "Platón y los poetas". Instituto de la Universidad de Antioquía, Bogotá: Editorial universitaria, 1991.

Hegel, G. W. F. Lecciones sobre la estética. Madrid: Akal, 2007. Medio impreso.

Heidegger, Martin. De L'Origine de L'oeuvre D'Arte (Premiére Version), París: Authentica, 1987. Medio impreso.

---. De la esencia de la verdad, Barcelona: Herder, 2007. Medio impreso.

---. “Der Ursprung des Kunstwerkes”. Holzwege (Ga 5), Frankfurt: V. Klostermann, 1977. Medio impreso. 
---. "El origen de la obra de arte". Arte y poesía. Trad. Samuel Ramos. México: Fondo de Cultura Económica, 2002. Medio impreso.

---. El Ser y el tiempo. Trad. J. Gaos. México: Fondo de Cultura Económica, 1980. Medio impreso.

---. "La doctrina platónica de la verdad". Hitos. Madrid: Alianza Editorial, 2000. Medio impreso.

---. Logik als die Frage nach dem Wesen der Sprache (Ga 58), Frankfurt: V. Klostermann, 1998. Medio impreso.

---. Logik. Die Frage nach der Wahrheit. Frankfurt: V. Klostermann, 1976. Medio impreso.

---. Sein und Wahrheit. Frankfurt: V. Klostermann, 2001. Medio impreso.

---. Sein und Zeit. Tubingen: Max Niemeyer Verlag, 1963. Medio impreso.

---. "Vom Ursprung des Kunstwerks: Erste Ausarbeitung". , Ciudad: editorial, 2002. Medio impreso.

---. Vom Wesen der Wahrheit. Zu Platons Höhlengleichnis und Theätet (WS 1931-1932), Frankfurt: V. Klostermann, 1988. Medio impreso.

Rossi, Luis Alejandro. "La Tierra y las imágenes de la comunidad ideal en El Origen de la obra de arte, de Martin Heidegger". Logos 38 (2005):143-167. Medio impreso.

Sobrevilla, David. "El origen de la obra de arte según Heidegger". Repensando la tradición Occidental. Lima: Amaru, 1986. Medio impreso.

Soneira, Ignacio. "Artes visuales y representación en la filosofía del arte de Martin Heidegger", XVI Congreso Nacional de Filosofía. AFRA. Universidad Nacional de Tres de Febrero. Centro Cultural Borges. Buenos Aires, 2013. Medio impreso.

---. “¿Cómo se dice la vida? La Dichtung como potencial solución a las dificultades a la analítica existenciaria". IX Jornadas del círculo de Fenomenología y Hermenéutica. Santa Fe-Paraná, 2012. Medio impreso.

---. Heidegger y el arte como lenguaje de la filosofía, Buenos Aires: Facultad de Filosofía y Letras, 2010. (Mimeo). Medio impreso.

Taminiaux, J., "The Origin of "The Origin of the Work of Art", en Sallis, J. Reading Heidegger, Indiana, University Press, 1993. Medio impreso.

Vattimo, G. Introducción a Heidegger, México, Gedisa, 1987. Medio impreso.

Volpi, F. "La Question du Logos dans 1' articulation de la facticité chez le jeune Heidegger, lecteur d'Aristote". Heidegger 1919-1929. De l'hermenuetique de la facticité á la méthaphysique du Dasein. Courtene, J-Francois (Comp.). Paris: Vrin, 1996. 22-36. Medio impreso. 